\title{
The release of tryptase from mast cells promote tumor cell metastasis via exosomes
}

\author{
Hui Xiao ${ }^{1}$, Mudan $\mathrm{He}^{2 \dagger}$, Guogang Xie ${ }^{1 \dagger}$, Yanan Liu ${ }^{3+}$, Yuxia Zhao ${ }^{4}$, Xiong Ye ${ }^{4^{*}}$, Xingjing $\mathrm{Li}^{2^{*}}$ and Min Zhang ${ }^{1^{*}}$ (D)
}

\begin{abstract}
Background: Cancer cells release exosomes and can be taken up by mast cells (MCs), but the potential functional effects of MCs on tumor metastasis remain unknown.

Method: Exosomes were isolated from the lung adenocarcinoma cell line A549, and the uptake of PKH26-labeled exosomes by bone marrow MCs was examined via flow cytometry and fluorescence microscopy. Cytokines and tryptase in MC supernatant were analyzed using an ELISA kit, and the presence of tryptase was evaluated by Western blotting. Cell proliferation and migration were determined through CCK-8 and transwell assays. Proteins in the tryptase-JAK-STAT signaling pathway were detected by Western blotting.

Results: In this study, we show that exosomes from A549 cells can be taken up by MCs. Moreover, A549 exosomes contain stem cell factor (SCF) to MCs and subsequently induce the activation of MCs through SCF-KIT signal transduction, which leads to MC degranulation and the release of tryptase. Tryptase accelerates the proliferation and migration of human umbilical vein endothelial cells (HUVECS) through the JAK-STAT signaling pathway.

Conclusions: Our results reveal a mechanism for metastasis in which exosomes can transfer SCF to and activate MCs, which can affect the release of tryptase and the angiogenesis of HUVECs.
\end{abstract}

Keywords: Lung cancer, Exosomes, Mast cell, Tryptase, Angiogenesis

\section{Highlights}

Exosomes derived from lung cancer cells possess SCF for binding to mast cells via KIT.

Mast cells release tryptase and are central mediators responsible for the progression of angiogenesis.

Exosomes can promote angiogenesis and tumor metastasis.

\footnotetext{
*Correspondence: ye-xiong@163.com; xingjingli618@163.com; minzhang20190123@163.com

${ }^{\dagger}$ Mudan He, Guogang Xie and Yanan Liu contributed equally to this work. ${ }^{4}$ College of Clinical Medicine, Shanghai University of Medicine \& Health Science, Shanghai, China

2Department of Respiratory and Critical Care Medicine, Shanghai General Hospital of Baoshan Branch, Shanghai, China

${ }^{1}$ Department of Respiratory and Critical Care Medicine, Shanghai General Hospital, Shanghai Jiaotong University, 85 Wujin Road, Shanghai 200080, China

Full list of author information is available at the end of the article
}

\section{Background}

Metastasis is the leading cause of lung cancer-related deaths. Angiogenesis or vascular permeability is a characteristic of the premetastatic niche that enables tumor cell colonization and promotes metastasis. Organs of future metastasis are selectively and actively modified by the primary tumor before metastatic spread [1]. Through complex cross-talk among primary tumor-derived factors and local stromal components, primary tumors create a favorable microenvironment in secondary organs for subsequent metastases [2]. Sowing the 'seeds' of metastasis requires tumor-shed exosomes that enable the 'soil' at distant metastases promote the capture and growth of circulating tumor cells [1]. Pancreatic ductal adenocarcinomaderived exosomes initiate premetastatic niche formation in the liver [3]. Moreover, tumor-conditioned lymphatic endothelial cells promote angiogenesis in these organs for breast cancer metastasis [4].

(c) The Author(s). 2019 Open Access This article is distributed under the terms of the Creative Commons Attribution 4.0 International License (http://creativecommons.org/licenses/by/4.0/), which permits unrestricted use, distribution, and reproduction in any medium, provided you give appropriate credit to the original author(s) and the source, provide a link to the Creative Commons license, and indicate if changes were made. The Creative Commons Public Domain Dedication waiver (http://creativecommons.org/publicdomain/zero/1.0/) applies to the data made available in this article, unless otherwise stated. 
Exosomes are nanosized lipid bilayer membrane vesicles $(30-150 \mathrm{~nm})$ that can released by various cells, such as mast cells (MCs) [5], dendritic cells [6], tumor cells $[7,8]$ and stem cells [9]. Exosomes are well known to transfer their contents, including shuttle functional RNA [10], proteins [11] and lipids [12] between cells. Importantly, the transfer of these molecules can alter the tumor microenvironment $[13,14]$ and play an important role in intercellular communication within the extracellular environment.

Emerging evidence shows that exosomes derived from tumor cells, including cells from lung cancer [15, 16], colon cancer [17, 18], melanoma [19-21], prostate cancer [22], breast cancer [4, 23] and pancreatic cancer [24] can play an important role in the interplay between immunocytes and tumor cells. Importantly, exosomes derived from lung cancer cells play key roles in tumor loading during metastatic cell seeding [25]. A great deal of evidence points to MCs having key roles in the development of metastases. Mast cell-derived KIT acts as a functional protein that interacts with tumor cells via exosomes and subsequently activates KIT-SCF signal pathway, which accelerates the proliferation in lung cancer cells [11]. However, little is known regarding the immediate fate of incoming lung cancer cell-derived exosomes as they first contact MCs, and even less is known regarding what happens in these exosometreated MCs. Furthermore, the mechanisms that may allow early-stage lung cancer cell-derived exosomes to complete the pretransfer from the microenvironment to MCs are unknown.

\section{Methods \\ BMMCs}

Bone marrow-derived MCs (BMMCs) were prepared as previously described [26, 27]. BMMCs were cultured in Roswell Park Memorial Institute (RPMI) 1640 medium (Corning, USA) supplemented with 10\% heat-inactivated fetal bovine serum (FBS) and $10 \mathrm{ng} / \mathrm{ml}$ recombinant interleukin-3 (rIL-3) (PeproTech, USA). Subsequently, the cells were harvested and observed to consist of $98 \%$ pure MCs as assessed by toluidine blue staining, CD117 and IgE receptor (FceRI) expression, confirming that BMMCs can be cultured and release exosomes [26-28].

\section{Cell culture}

The lung adenocarcinoma cell lines A549 and HUVEC cells were obtained from the American Type Culture Collection (ATCC). A549 cells were maintained in Kaighn's Modification of Ham's F-12 Medium (F-12 K medium; Gibco, USA), and HUVEC cells were cultured in Dulbecco's Modified Eagle Medium (DMEM; Gibco, USA) supplemented with $10 \%$ exosome-depleted FBS (Viva Cell Biosciences, Qipeng, Shanghai, China) and
$100 \mathrm{U} / \mathrm{ml}$ penicillin and $100 \mu \mathrm{g} / \mathrm{ml}$ streptomycin. The cells were maintained in a humidified incubator at $37^{\circ} \mathrm{C}$ with $5 \% \mathrm{CO}_{2}$.

\section{Isolation of exosomes}

The A549 cell culture media were collected 3 days after the start of the incubation. The medium was harvested and centrifuged at $1500 \mathrm{rpm}$ for $10 \mathrm{~min}$ to remove the cells. Subsequently, the medium was centrifuged at 14 , $500 \mathrm{RCF}$ for $20 \mathrm{~min}$ at $4{ }^{\circ} \mathrm{C}$ and then filtered through a $0.2 \mu \mathrm{m}$ filter (Merck Millipore, Cork, Ireland) to remove cell debris and larger vesicles. Exosomes were sedimentation by ultracentrifugation at $120,000 \times \mathrm{g}$ for $70 \mathrm{~min}$, and the exosome pellets were resuspended in $150 \mu \mathrm{l}$ phosphate buffered saline (PBS) and frozen at $-80^{\circ} \mathrm{C}$.

\section{Transmission electron microscopy analysis}

Transmission electron microscopy analyses were performed as previously described [29]. Exosomes from A549 cells were loaded onto carbon-coated 200-mesh, thin-bar copper grids and post-fixed in $2.5 \%$ glutaraldehyde, washed, contrasted in $2 \%$ uranylacetate, embedded in a mixture of uranyl acetate $(0.4 \%)$, and examined in a LEO 912AB Omega electron microscope (Carl Zeiss NTS, Oberkochen, Germany).

\section{Degranulation assay of $\beta$-hexosaminidase release rate}

BMMCs $\left(5 \times 10^{5}\right.$ cells $\left./ \mathrm{ml}, 0.5 \mathrm{ml}\right)$ were incubated in a 24-well plate for routine culturing, with three parallel wells used for each group. The cells were centrifuged and resuspended three times in $500 \mu \mathrm{l}$ Tyrode's solution. Different concentrations (10 or $50 \mathrm{ng} / \mathrm{ml}$ ) of human stem cell factor (SCF; PeproTech, USA), $20 \mu \mathrm{g}$ of exosomes derived from A549 cells or the same amount of PBS were added to the cells, which were subsequently incubated at $37^{\circ} \mathrm{C}$ for $24 \mathrm{~h}$. The exosome group included four subgroups that were incubated for 4, 8, 12 or $24 \mathrm{~h}$. The reactions were terminated after the cells were incubated for $10 \mathrm{~min}$ in an ice bath. The supernatant of each well was transferred into a 96-well plate, and the absorbance of each well was measured at $405 \mathrm{~nm}$ after adding $50 \mu \mathrm{l}$ of the substrate (p-nitrophenyl-N-acetyl-beta-Dglucosaminide; Aladdin, China), incubating at $37^{\circ} \mathrm{C}$ for $60 \mathrm{~min}$ and then adding $150 \mu \mathrm{l}$ of the stop buffer (200 $\mathrm{mmol} / \mathrm{L}$ glycine, $\mathrm{pH} 10.4)$. After discarding the supernatant, $200 \mu \mathrm{l}$ Triton $\mathrm{X}-100(0.5 \%)$ was added to each well $(30 \mathrm{~min})$, after which the lysate was centrifuged at $10,000 \times \mathrm{g}$ for $30 \mathrm{~min}$. Subsequently, the absorbance of the lysate supernatant was determined for each sample. The release of $\beta$-hexosaminidase (\%) was reported as the supernatant absorbance divided by that of the supernatant of the cell lysate. 


\section{Uptake of A549 exosomes by BMMCs}

To monitor exosome uptake kinetics, exosomes derived from A549 cells were labeled with the red fluorescent dye PKH26 (Sigma-Aldrich). In brief, isolated exosomes from A549 cells labeled PKH26 dye $(20 \mu \mathrm{g})$ were washed three times using $100 \mathrm{kDa}$ Vivaspin filters (Millipore, USA) to eliminate excess dye and were then added to $2.5 \times 10^{5}$ cells $/ \mathrm{ml}$ BMMCs cultured on the confocal plate. PBS was mixed with PKH26 and added to the cells as a control for nonspecific labeling. BMMCs were harvested at different time points $(1,2$, $4,8,12$ and $24 \mathrm{~h}$ ) and analyzed by flow cytometry. For the flow cytometry analysis, BMMCs were washed twice with PBS and treated with a $0.25 \%$ trypsin to detach the cells. Subsequently, the cells were washed three with 1\% BSA-PBS acquired in Beckman Coulter FC500 instruments and analyzed with FlowJo software. For fluorescence microscopy (DMi8; Leica, GER), BMMCs were washed twice with PBS, and fixed with a $4 \%$ formaldehyde solution for $15 \mathrm{~min}$ and then washed again twice with PBS. The cells were supplemented with a DAPI staining solution (Beyotime, China) to label cell nuclei.

\section{Determination of cytokine levels}

BMMCs $\left(5 \times 10^{5}\right.$ cells $\left./ \mathrm{ml}, 2 \mathrm{ml}\right)$ were incubated in the 6well cell culture plate with media overnight. Subsequently, medium, SCF (100 ng) and A549 cell-derived exosomes $(40 \mu \mathrm{g})$ were added to BMMCs. After incubating for $24 \mathrm{~h}$, the cell supernatants were collected in ultrafiltration tubes $(50,10$, or $3 \mathrm{kDa}$; Millipore, USA) according to the formula weight of the cytokines. The cell supernatants were collected for ELISA after centrifuging at $2000 \times \mathrm{g}$ for $6 \mathrm{~min}$. The levels of tryptase, interleukin-6 (IL-6), matrix metallopeptidase-9 (MMP-9) and tumor necrosis factor alpha (TNF- $\alpha$ ) were determined using an ELISA kit (RND, USA) according to the manufacturer's instructions.

\section{Western blot analysis}

The supernatant of BMMCs $\left(5 \times 10^{5}\right.$ cells $\left./ \mathrm{ml}, 2 \mathrm{ml}\right)$ was collected after incubating overnight and was then incubated with media, SCF (100 ng) and A549 cell-derived exosomes $(40 \mu \mathrm{g})$ as described for the ELISA test. The protein in the cell supernatants was extracted using methanol and chloroform. After measuring the protein concentration, $20 \mu \mathrm{g}$ of protein was subjected to SDS-

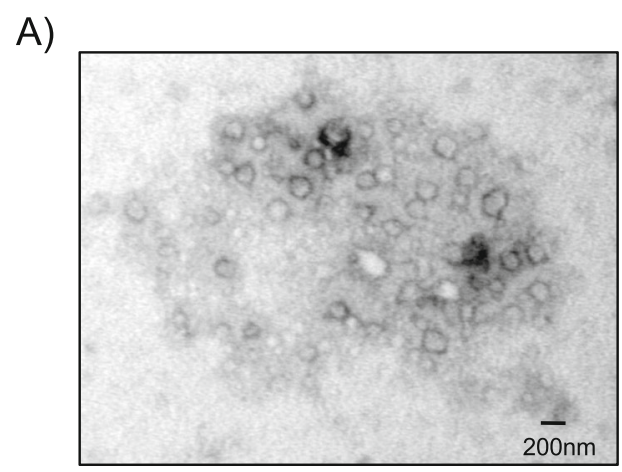

B)
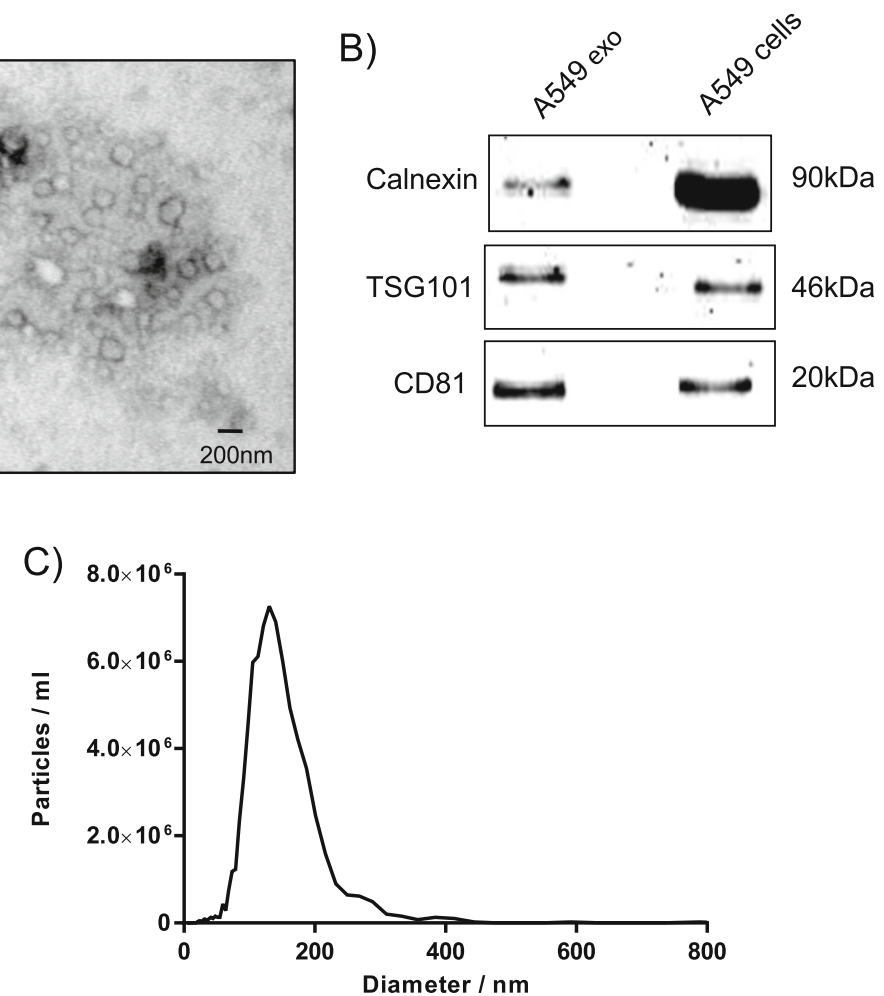

Fig. 1 Identification and characterization of A549 cell-derived exosomes. Exosomes were isolated using differential centrifugation. a The electron micrographs of the exosomes revealed rounded structures with a size of approximately 30-150 nm. The scale bar represents $200 \mathrm{~nm}$. $\mathbf{b}$ Western blot analysis of exosomes derived from the supernatant of A549 cells shows the presence of the common exosomes proteins CD81, calnexin and TSG101. Cells were used as a control. c The sizes of exosomes derived from the supernatant of A549 cells were analyzed using nanoparticle tracking analysis 
A)

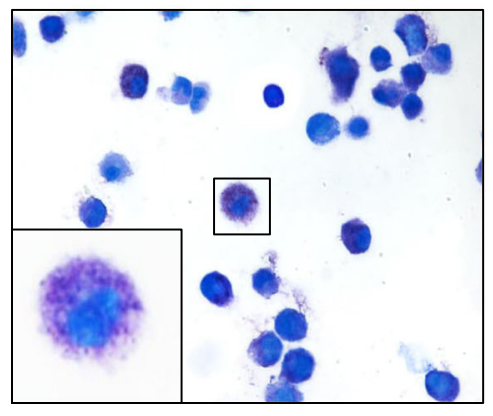

C)
B)

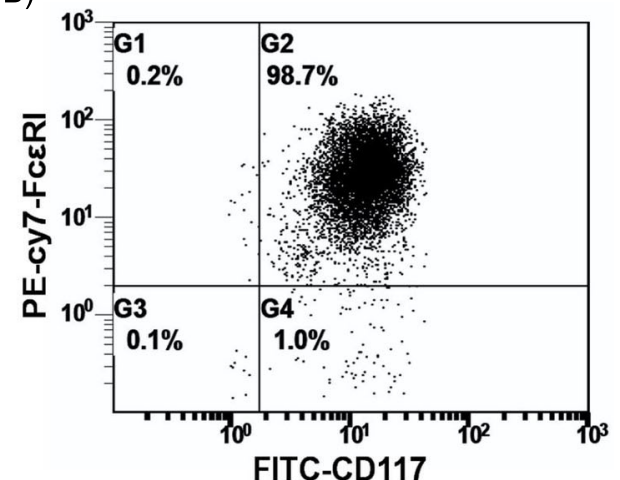

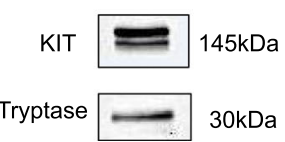

Fig. 2 Characteristics of bone marrow mast cells. a Bone marrow mast cells (BMMCs) showed abundant purple granules following toluidine blue staining (400x). b BMMCs were positive for CD117 and IgE receptor (FceRI) by flow cytometry analysis. c The Western blotting analysis indicated that BMMCs expressed KIT and tryptase

PAGE and transferred to PVDF membranes (GE Healthcare, Piscataway, NJ, USA). PVDF membranes were blocked in $5 \%$ bovine serum albumin in Tris-buffered saline with Tween 20 (BSA-TBST) for $2 \mathrm{~h}$. The membranes were then incubated overnight at $4{ }^{\circ} \mathrm{C}$ with the primary rabbit anti-human antibodies diluted in 5\% BSA-TBST: anti-CD81, anti-SCF and anti-calnexin (Santa Cruz Biotechnology), anti-KIT (Abcam, USA), anti-tryptase (Proteintech, China), anti-JAK, anti-p-JAK, anti-STAT and anti-p-STAT(Cell Signaling Technology
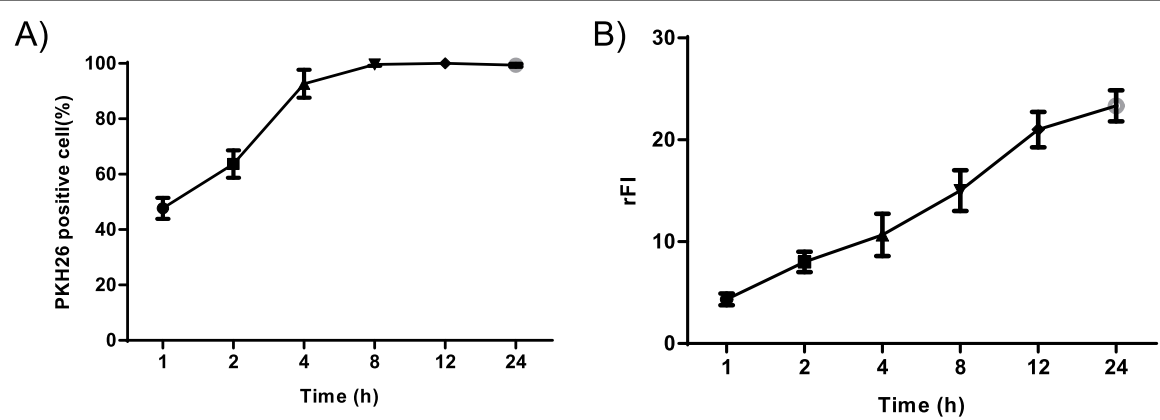

C)
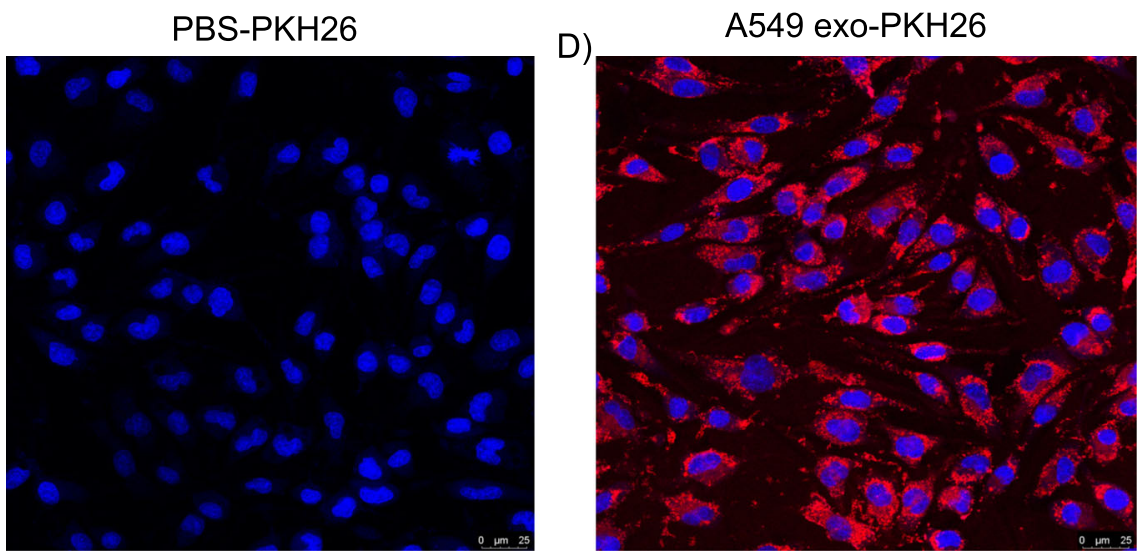

Fig. 3 Uptake of A549 cell-derived exosomes by mast cells. a and $\mathbf{b}$ The percent positive cells and relative fluorescence intensity (rFI) data for different time points were determined with flow cytometry for $1-24 \mathrm{~h}$ and are shown as the means \pm SEM ( $n=3$ ). $\mathbf{c}$ and $\mathbf{d}$ ) Uptake of PKH26-PBS control and PKH26-labeled exosomes by fluorescence microscopy imaging. Nuclei were stained with DAPI (blue) 
Inc). The membranes were washed 3 times for 5 min each before being incubated with the secondary antibody for $2 \mathrm{~h}$. The secondary antibody was goat anti-rabbit IgG (horseradish peroxidase (HRP)-conjugated, Proteintech, China) diluted in 5\% BSA-TBST. The membrane was washed 3 times for $5 \mathrm{~min}$ each before being analyzed using the ClarityTM ECL Western Blotting Detection System (Bio-Rad Laboratories). The relative intensity for p-JAK and p-STAT was calculated as follows: (phosphorylated protein/GAPDH)/(total protein/GAPDH).

\section{Detection of cell proliferation}

Human umbilical vein endothelial cells (HUVECs; $5 \times 10^{4}$ cells/well) in monoculture were stimulated with tryptase $(50 \mathrm{ng} / \mathrm{ml})$ and different supernatants $(10 \mu \mathrm{l})$ from BMMCs incubated with SCF- and exosomes derived from A549 cells for 24, 48 and $72 \mathrm{~h}$. Cell proliferation was detected using a Cell Counting Kit-8 (CCK-8; Dojindo, Shanghai, China) according to the manufacturer's protocol. The absorbance was a measured at $450 \mathrm{~nm}$ using a spectrophotometer (Spectrum Max; Molecular Devices, Pulang, Beijing, China). The results were normalized as a percent to the control.

\section{Wound healing assay}

HUVECs were cultured in Dulbecco's modified Eagle's medium (DMEM) in six-well plates $\left(1 \times 10^{5}\right.$ cells $\left./ \mathrm{ml}\right)$, with $500 \mu \mathrm{l}$ of cell suspension and $2 \mathrm{ml}$ of FBS-depleted DMEM exosome-complete medium were added to each well. When the cell abundance reached $90 \%$, cells were starved for $12 \mathrm{~h}$ with serum-free DMEM. Subsequently, a wound was made in each well with a $200-\mu l$ plastic pipette tip. After being washed three times with PBS, the cells were cultured with serum-free DMEM. In addition, a well-balanced transwell chamber (Millipore Corporation, USA; pore size $0.4 \mathrm{um}$ ) was placed in the six-well plates. Tryptase $(50 \mathrm{ng} / \mathrm{ml})$ and the cell supernatant of SCF- and exosome-stimulated cells were inoculated into the upper chamber of each plate. Cell growth was monitored at $0,12,24,48$ and $72 \mathrm{~h}$. The wound width was

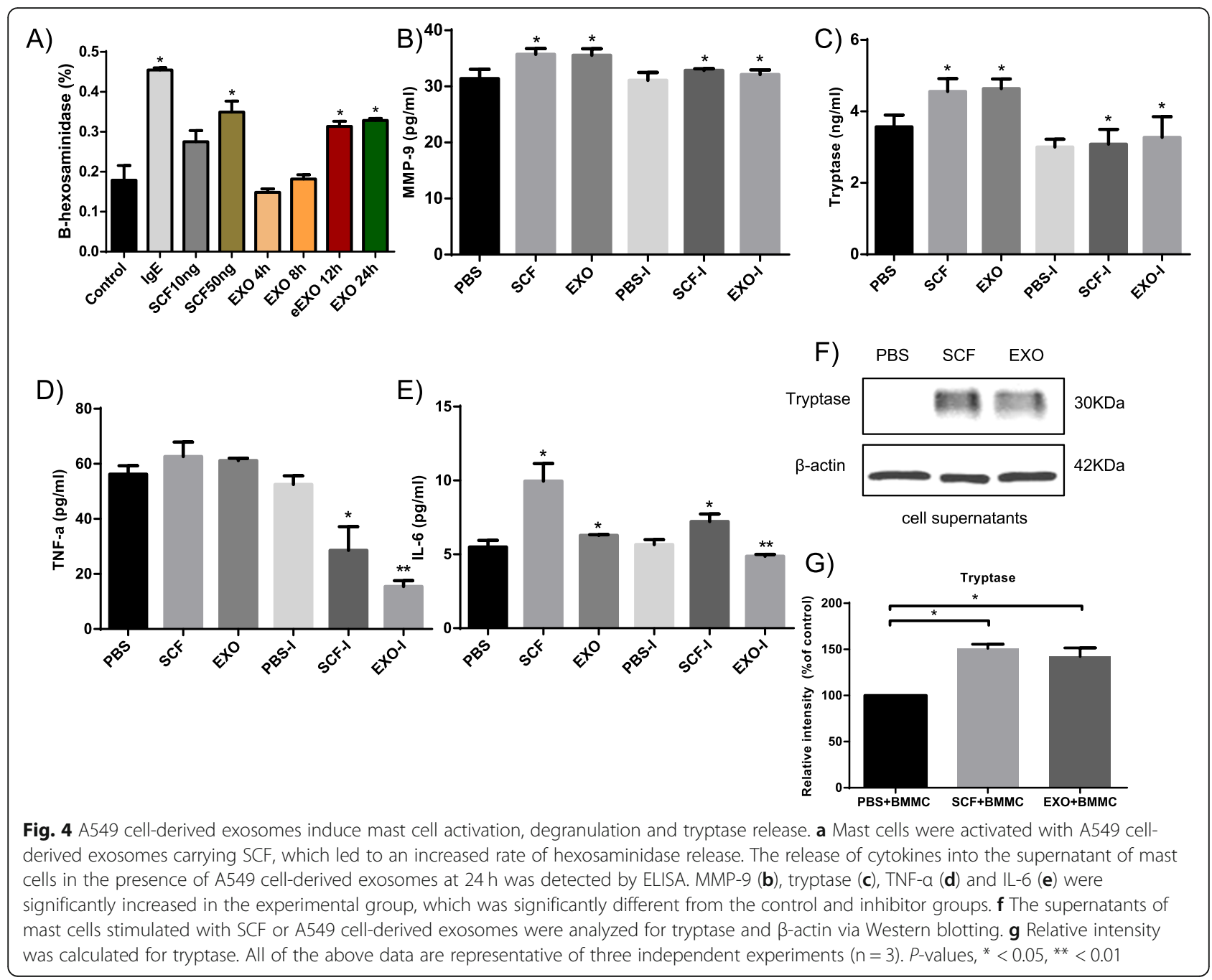


then observed in each well at each time point and measured using a Leica LAS V3.7 imaging system.

\section{Statistical methods}

The statistical analyses and graphs were generated using GraphPad (GraphPad Software Prism 6, La Jolla, USA). The statistical analyses of western blot were performed using Students t-test. Student's t-test was used to analyze the differences between two groups, and Kruskal Wallis tests were used to compare among three or more groups. All tests of statistical significance were 2-sided with a significance level set at $<0.05$.

\section{Results}

Identification of lung cancer cell exosomes and BMMCs

Vesicular round structures were visualized by electron microscopy after isolating exosomes from the supernatant of cultured A549 cells using ultracentrifugation (Fig. 1a). The exosome traditional markers were positive for CD81, TSG101 and calnexin (Fig. 1b). The characterization of exosomes by nanoparticle tracking analysis showed an average particle size of approximately $130 \mathrm{~nm}$ (Fig. 1c). These exosomes were therefore considered appropriate for use in this study.
BMMCs were generated in the presence of IL-3 after being cultured for 4 weeks. Figure 2a shows the morphology of BMMCs containing an abundance of purple granules after toluidine blue staining. Flow cytometry analysis was also performed to identify MCs based on the expression of CD117 and FceR1, the results of which suggested that over $98.7 \%$ of the cells were MCs (Fig. 2b). BMMCs were positive for the protein markers KIT and tryptase (Fig. 2c), indicating that the cells could be utilized for subsequent experiments.

\section{Effect of lung cancer cell exosomes on MCs}

To examine whether exosomes from lung cancer cells can be taken up by MC, exosomes from A549 cells were labeled with PKH26 dye and added to BMMC cultures. Flow cytometry analysis showed an increase in the fluorescence intensity of BMMC after addition of lung cancer cell-derived exosomes, indicating cellular uptake (Fig. 3a). Eight hours after the addition of the stained exosomes, the fluorescence of BMMC was markedly increased with time (Fig. 3b), indicating that BMMC began exosomal uptake. Uptake of fluorescent exosomes by BMMC was also observed by fluorescence microscopy (Fig. 3c and d).

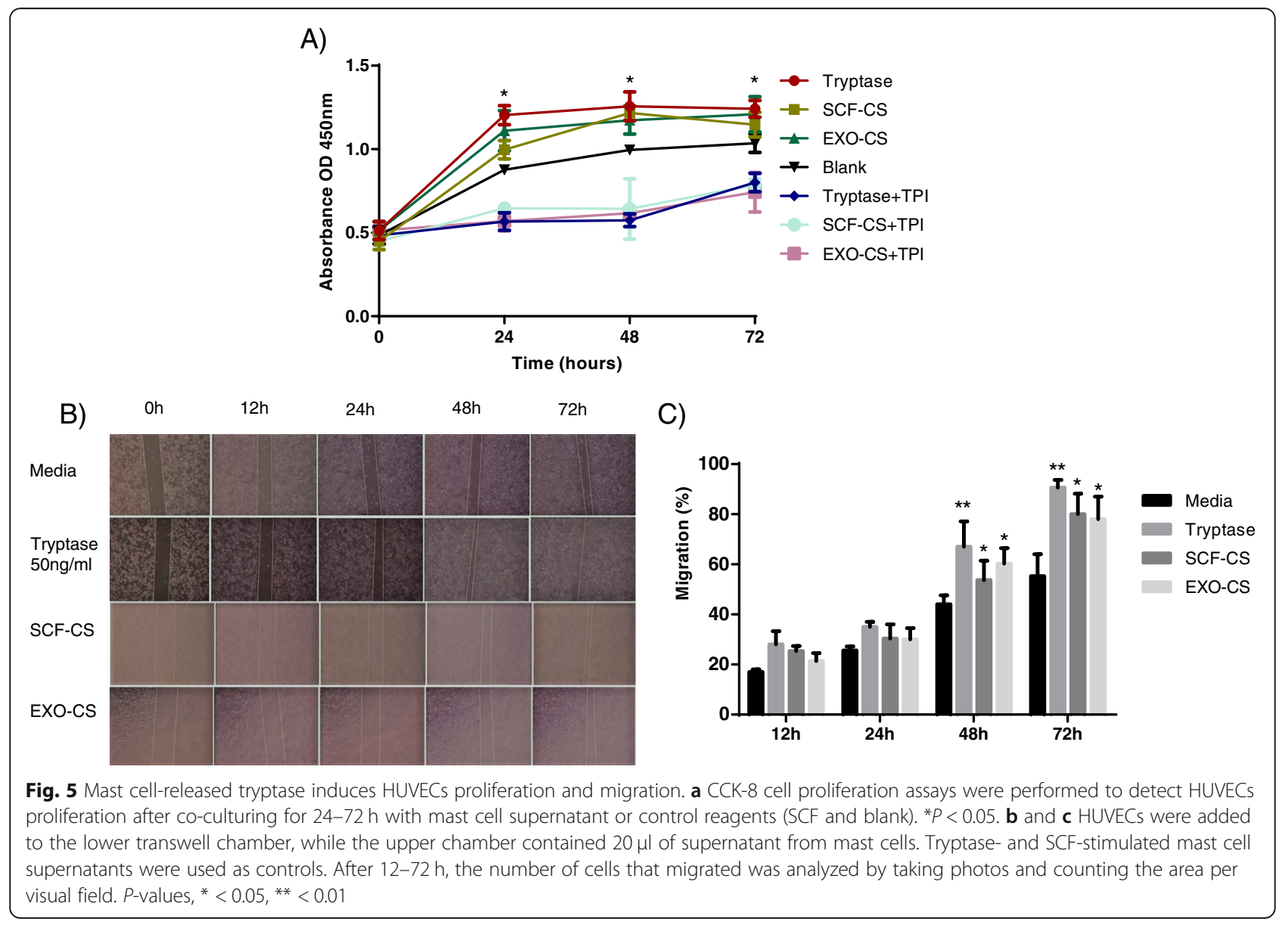


To determine whether exosomes from lung cancer cells influence MCs, the presence of specific proteins and cytokines was assessed in the supernatants of MCs in the presence of A549 cell-derived exosomes. First, A549 cell-derived exosomes were added to BMMCs in culture at different time points $(4,8,12$ and $24 \mathrm{~h})$, and the release of $\beta$-hexosaminidase was used to evaluate the extent of degranulation (Fig. 4a). The percentage of BMMCs degranulation was significantly increased (by $200 \%$ ) in response to the treatment with A549 cellderived exosomes $(20 \mu \mathrm{g})$ for $24 \mathrm{~h}$, a result that is consistent with the optimal incubation time described above. SCF (10 ng and $50 \mathrm{ng}$ ) and IgE were used as positive controls. The production of MMP-9, tryptase, IL-6 and TNF- $\alpha$ in cell supernatants was significantly increased by the treatment of BMMCs with exosomes compared to the PBS control and inhibitor, as quantified using an ELISA kit $(P<0.05)$ (Fig. 4b-e). Second, the MC supernatants were positive for the protein tryptase in the presence of A549 cell-derived exosomes or SCF (Fig. 4f) compared with the negative control (Fig. 4g).

\section{Detection of tryptase in MC supernatants and activation of the JAK-STAT signaling pathway in HUVECs}

To determine whether supernatants of BMMCs stimulated by SCF or A549 cell-derived exosomes affected HUVECs, the cell supernatants were added to cultured HUVECs for 24,48 , and $72 \mathrm{~h}$ in the presence of CCK- 8 to evaluate their effect on cell proliferation. The proliferation of HUVECs was significantly enhanced on the presence of tryptase, cell supernatants stimulated by A549 cell-derived exosomes or SCF compared to that of cells treated with the control medium and the inhibitor, as quantified using an ELISA kit (Fig. 5a).

To examine the effects of the supernatants of BMMCs stimulated by SCF or A549 cell-derived exosomes on HUVECs, HUVECs were seeded onto the membrane of a upper transwell chamber and with tryptase, SCF-cell supernatant (CS) and exosome (EXO)-CS present in the lower chamber to evaluate the capacity of tryptase to induce migration. Significantly more cells migrated into the lower chamber in the presence of tryptase than was observed in the control at 48 and $72 \mathrm{~h}$ (Fig. 5b and c).

To propose a molecular model for the observed proliferation and migration of HUVECs, we attempted to identify the pathways activated by the addition of tryptase. As shown in Fig. 6a, we observed increased phosphorylation of JAK and STAT when tryptase, SCF-CS, and EXO-CS were added compared to that with media alone. Furthermore, the total amounts of JAK and STAT were unchanged according to the analysis of the Western blot. Thus, tryptase, SCF-CS and EXO-CS may activate the proliferation of HUVECs through the JAK-STAT pathway.

\section{Discussion}

Metastasis is one of the basic characteristics of tumors. Tumor tissues contain many immune cells, including
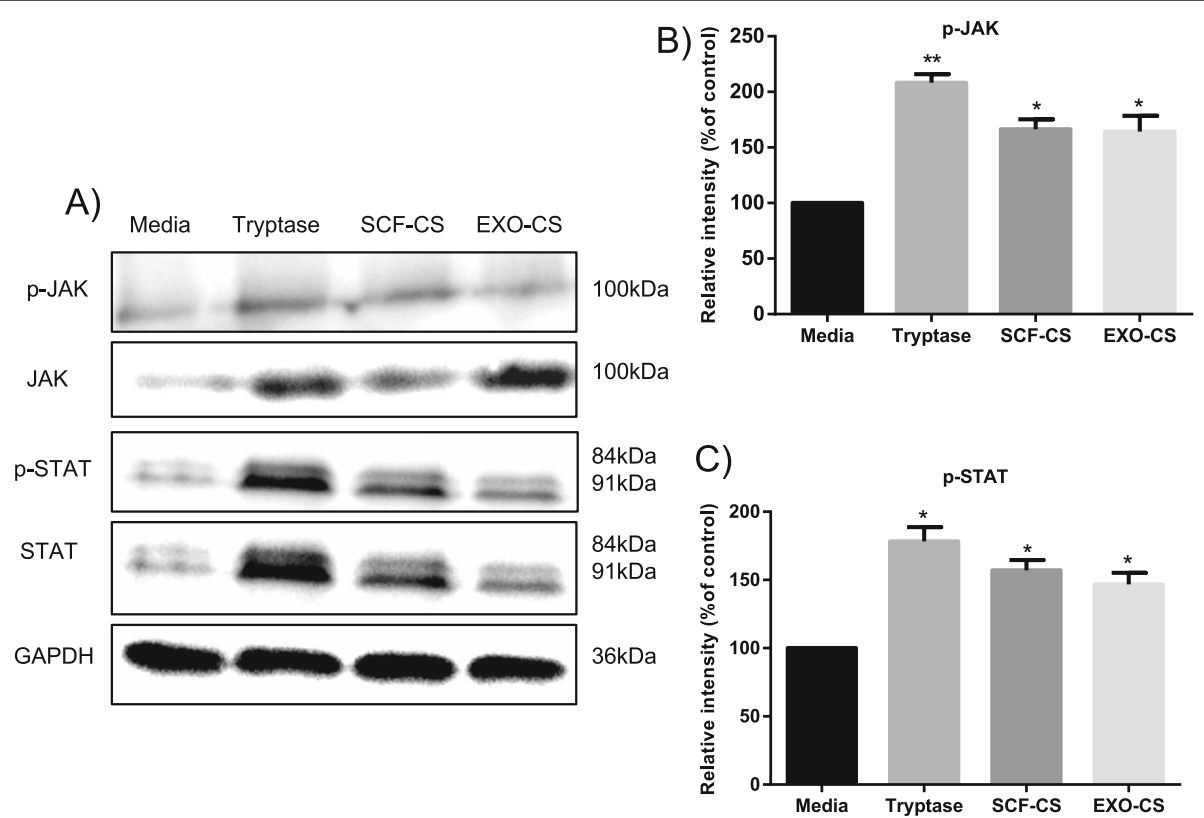

Fig. 6 Mast cell supernatant activates the JAK-STAT signaling pathway in HUVECs. a HUVECs treated with supernatants from mast cells stimulated with SCF or A549 cell-derived exosomes were analyzed via Western blotting and were compared with HUVECs treated with medium and tryptase. Phosphorylated (p)-JAK and p-STAT and total JAK and STAT were measured by Western blotting and protein loading was normalized, with the samples also probed for GAPDH. $\mathbf{b}$ and $\mathbf{c}$ Relative intensity was calculated for p-JAK and p-STAT. All of the above data are representative of three independent experiments $(n=3)$. ${ }^{*} P<0.05$ and ${ }^{* *} P<0.01$ 
MCs. It has been suggested that exosomes can shuttle RNA, microRNA and proteins between cells, which is a process that is likely to be highly active in cell-to-cell signaling in tumors. However, little is known regarding how MCs may act to specifically promote cancer metastasis. In this study, we observed that exosomes derived from the lung adenocarcinoma cell line A549 contain the SCF receptor, which can be transferred to MCs via exosomes. Specifically, we showed that lung cancer cells release exosomes with typical exosome markers, such as TSG101, CD81 and calnexin. The lung cancer cellreleased exosomes were rapidly taken up by BMMCs, a process that peaks after approximately $12 \mathrm{~h}$. Importantly, BMMCs were observed to contain the natural SCF receptor KIT, which induced the activation and degranulation of BMMCs. The release of tryptase promotes the proliferation and migration of HUVECs to form the premetastatic microenvironment for lung cancer. Furthermore, tryptase derived from MCs enhanced the JAK-STAT signaling pathway activity. Overall, these data suggest that exosomes from lung cancer cells enhance the proliferation of HUVECs by activating MCs and the SCF-KIT-induced release of tryptase, potentially by enhancing JAK-STAT signaling in HUVECs.

In this study, we confirmed the ability of lung cancer cells to release exosomes into their microenvironment and their uptake by BMMCs. The electron micrographs and nanoparticle tracking analysis of exosomes revealed the presence of rounded structures with a size of approximately $30-150 \mathrm{~nm}$, similar to previously described reports [30, 31]. Exosomes derived from lung cancer cells had typical exosome markers, such as CD81, TSG101 and calnexin, which fits with the previously reported protein content for exosomes. The observed uptake was rapid, as more than $45 \%$ of cells had already taken up some exosomes after one hour, and almost all cells were positive for exosomes after eight hours. However, the uptake of exosomes continued over time, as measured by the relative fluorescence intensity, and peaked at $12-24 \mathrm{~h}$ after the addition of exosomes. This time course of uptake was slightly slower than what we have previously reported [32].

Although endogenously produced exosomes may have a role in tumors, the associated mechanism is not fully understood. As expected, A549 cell-derived exosomes activated the release of proinflammatory mediators, such as $\beta$-hexosaminidase, tryptase, MMP-9, TNF- $\alpha$ and IL-6 from activated MCs. To exclude the possibility of the influence of other cytokines and proteins from the cell supernatants, we assayed the effect of tryptase from the cell supernatants in the current study. Protease activated receptor 2 (PAR2) expressed by HUVECs can be activated by serine proteases, such as the MC mediator tryptase. In the current study, we showed that active
BMMC-derived tryptase enhanced the proliferation and migration capacity of HUVECs in a coculture system. Based on previously published data on the mitogenic properties of tryptase, we speculated that the changes in HUVEC migration could be due to an increased cell proliferation rate. Accordingly, the binding of tryptase to PAR2 could upregulate the phosphorylation of JAK and STAT, which is regarded as a partial signaling cascade in activated HUVECs.

The shortcomings of this study were activated MCs release many molecules, such as cytokines and proteins that play many key roles in angiogenesis. This study focused only on the effect of tryptase on HUVECs.

Our current series of studies are mainly focused on the SCF-containing exosomes from a lung cancer cell line (A549) and showed that these exosomes can be taken up by MCs. This uptake leads to the activation of MCs, which release tryptase to enhance the proliferation and migration of HUVECs by activating the JAK-STAT signaling pathway. Future work can elucidate the molecular mechanisms leading to the release of exosomes from cancer cells. Furthermore, it is essential to understand the formation of the tumor metastasis microenvironment and the targeting of metastatic organs from different tumor cell-derived exosomes.

\section{Conclusions}

Our results reveal a mechanism for metastasis in which exosomes can transfer SCF to and activate MCs, which can affect the release of tryptase and the angiogenesis of HUVECs activating the JAK-STAT signaling pathway.

\section{Abbreviations}

BMMCs: Bone marrow mast cells; CS: Cell supernatant; FBS: Fetal bovine serum; GAPDH: Glyceraldehyde 3-phosphate dehydrogenase;

HUVECs: Human umbilical vein endothelial cells; SCF: Stem cell factor

\section{Acknowledgements}

None.

\section{Authors' contributions}

HX contributed to the study design, interpretation of the results and drafted the manuscript. $\mathrm{MH}$ and GX performed the most of the in vitro cell culture experiments and performed the migration assay. $X Y$ and $Y L$ contributed to the data analysis. MZ and $X L$ conceived the study. $Y Z$ supported the fluorescence microscopy experiments. All authors read and approved the final manuscript.

\section{Funding}

This works that collection; analysis and interpretation of data were supported by the National Natural Science Foundation of China (No. 81701547) and the Beijing Medical and Health Foundation (No. YWJKJJHKYJJ-F2187E).

Availability of data and materials

The datasets obtained and/or analyzed during the current study are available from the corresponding author upon reasonable request.

Ethics approval and consent to participate Not applicable 


\section{Consent for publication}

Not applicable

\section{Competing interests}

The authors declare that they have no competing interests.

\section{Author details}

'Department of Respiratory and Critical Care Medicine, Shanghai General Hospital, Shanghai Jiaotong University, 85 Wujin Road, Shanghai 200080, China. ${ }^{2}$ Department of Respiratory and Critical Care Medicine, Shanghai General Hospital of Baoshan Branch, Shanghai, China. ${ }^{3}$ Department of Clinical Laboratory, Shanghai Children's Hospital, Shanghai Jiaotong University, Shanghai, China. ${ }^{4}$ College of Clinical Medicine, Shanghai University of Medicine \& Health Science, Shanghai, China.

\section{Received: 27 March 2019 Accepted: 24 September 2019}

\section{Published online: 29 October 2019}

\section{References}

1. Peinado $H$, Zhang $H$, Matei IR, Costa-Silva B, Hoshino A, Rodrigues G, et al. Pre-metastatic niches: organ-specific homes for metastases. Nat Rev Cancer. 2017;17(5):302-17.

2. Liu Y, Cao X. Characteristics and significance of the pre-metastatic niche. Cancer Cell. 2016:30(5):668-81.

3. Costa-Silva B, Aiello NM, Ocean AJ, Singh S, Zhang H, Thakur BK, et al. Pancreatic cancer exosomes initiate pre-metastatic niche formation in the liver. Nat Cell Biol. 2015;17(6):816-26.

4. Lee E, Fertig EJ, Jin K, Sukumar S, Pandey NB, Popel AS. Breast cancer cells condition lymphatic endothelial cells within pre-metastatic niches to promote metastasis. Nat Commun. 2014;5:4715.

5. Skokos D, Goubran-Botros H, Roa M, Mecheri S. Immunoregulatory properties of mast cell-derived exosomes. Mol Immunol. 2002;38(1618):1359-62.

6. Pitt JM, Andre F, Amigorena S, Soria JC, Eggermont A, Kroemer G, et al. Dendritic cell-derived exosomes for cancer therapy. J Clin Invest. 2016; 126(4):1224-32.

7. Aslan C, Maralbashi S, Salari F, Kahroba H, Sigaroodi F, Kazemi T, Kharaziha P. Tumor-derived exosomes: implication in angiogenesis and antiangiogenesis cancer therapy. J Cell Physiol. 2019;234(10):16885-903.

8. Z Zheng H, Zhan Y, Liu S, Lu J, Luo J, Feng J, et al. The roles of tumor-derived exosomes in non-small cell lung cancer and their clinical implications. J Exp Clin Cancer Res. 2018;37(1):226.

9. Sharma A. Role of stem cell derived exosomes in tumor biology. Int J Cancer. 2018:142(6):1086-92.

10. Valadi H, Ekstrom K, Bossios A, Sjostrand M, Lee JJ, Lotvall JO. Exosomemediated transfer of mRNAs and microRNAs is a novel mechanism of genetic exchange between cells. Nat Cell Biol. 2007;9(6):654-9.

11. Xiao H, Lasser C, Shelke GV, Wang J, Radinger M, Lunavat TR, et al. Mast cell exosomes promote lung adenocarcinoma cell proliferation - role of KITstem cell factor signaling. Cell Commun Signal. 2014;12:64.

12. Skotland T, Hessvik NP, Sandvig K, Llorente A. Exosomal lipid composition and the role of ether lipids and phosphoinositides in exosome biology. J Lipid Res. 2019;60(1):9-18.

13. Maia J, Caja S, Strano Moraes MC, Couto N, Costa-Silva B. Exosome-based cell-cell communication in the tumor microenvironment. Front Cell Dev Biol. 2018;6:18

14. Hu C, Chen M, Jiang R, Guo Y, Wu M, Zhang X. Exosome-related tumor microenvironment. J Cancer. 2018;9(17):3084-92.

15. Frydrychowicz M, Kolecka-Bednarczyk A, Madejczyk M, Yasar S, Dworacki G. Exosomes - structure, biogenesis and biological role in non-small-cell lung cancer. Scand J Immunol. 2015:81(1):2-10.

16. Lobb RJ, van Amerongen R, Wiegmans A, Ham S, Larsen JE, Moller A. Exosomes derived from mesenchymal non-small cell lung cancer cells promote chemoresistance. Int J Cancer. 2017:141(3):614-20.

17. Lucchetti D, Calapa F, Palmieri V, Fanali C, Carbone F, Papa A, et al. Differentiation affects the release of Exosomes from Colon Cancer cells and their ability to modulate the behavior of recipient cells. Am J Pathol. 2017; 187(7):1633-47.

18. Zhao L, Yu J, Wang J, Li H, Che J, Cao B. Isolation and identification of miRNAs in exosomes derived from serum of colon cancer patients. $J$ Cancer. 2017:8(7):1145-52.
19. Bland CL, Byrne-Hoffman CN, Fernandez A, Rellick SL, Deng W, Klinke D 2nd. Exosomes derived from B16F0 melanoma cells alter the transcriptome of cytotoxic T cells that impacts mitochondrial respiration. FEBS J. 2018; 285(6):1033-50.

20. Somasundaram R, Herlyn M. Melanoma exosomes: messengers of metastasis. Nat Med. 2012;18(6):853-4.

21. Xiao D, Barry S, Kmetz D, Egger M, Pan J, Rai SN, et al. Melanoma cellderived exosomes promote epithelial-mesenchymal transition in primary melanocytes through paracrine/autocrine signaling in the tumor microenvironment. Cancer Lett. 2016;376(2):318-27.

22. Karlsson T, Lundholm M, Widmark A, Persson E. Tumor cell-derived Exosomes from the prostate Cancer cell line TRAMP-C1 impair osteoclast formation and differentiation. PLoS One. 2016:11(11):e0166284.

23. Bubnov R, Polivka J Jr, Zubor P, Konieczka K, Golubnitschaja O. "premetastatic niches" in breast cancer: are they created by or prior to the tumour onset? "Flammer syndrome" relevance to address the question. EPMA J. 2017;8(2):141-57.

24. Linton SS, Abraham T, Liao J, Clawson GA, Butler PJ, Fox T, et al. Tumorpromoting effects of pancreatic cancer cell exosomes on THP-1-derived macrophages. PLoS One. 2018;13(11):e0206759.

25. Headley MB, Bins A, Nip A, Roberts EW, Looney MR, Gerard A, et al. Visualization of immediate immune responses to pioneer metastatic cells in the lung. Nature. 2016;531(7595):513-7.

26. Li F, Wang Y, Lin L, Wang J, Xiao H, Li J, et al. Mast cell-derived Exosomes promote Th2 cell differentiation via OX40L-OX40 ligation. J Immunol Res. 2016:2016:3623898.

27. Xie G, Yang H, Peng X, Lin L, Wang J, Lin K, et al. Mast cell exosomes can suppress allergic reactions by binding to IgE. J Allergy Clin Immunol. 2018; 141(2):788-91.

28. Liang Y, Qiao L, Peng X, Cui Z, Yin Y, Liao H, et al. The chemokine receptor CCR1 is identified in mast cell-derived exosomes. Am J Transl Res. 2018; 10(2):352-67.

29. Chakrabortty SK, Prakash A, Nechooshtan G, Hearn S, Gingeras TR. Extracellular vesicle-mediated transfer of processed and functional RNY5 RNA. RNA. 2015:21(11):1966-79.

30. Alipoor SD, Mortaz E, Varahram M, Movassaghi M, Kraneveld AD, Garssen J, et al. The potential biomarkers and immunological effects of tumor-derived Exosomes in lung Cancer. Front Immunol. 2018:9:819.

31. Zhu MC, Xiong P, Li GL, Zhu M. Could lung cancer exosomes induce apoptosis of natural killer cells through the p75NTR-proNGF-sortilin axis? Med Hypotheses. 2017;108:151-3.

32. Ekstrom $\mathrm{K}$, Valadi $\mathrm{H}$, Sjostrand M, Malmhall C, Bossios A, Eldh M, et al. Characterization of mRNA and microRNA in human mast cell-derived exosomes and their transfer to other mast cells and blood CD34 progenitor cells. J Extracell Vesicles. 2012;1. https://doi.org/10.3402/jev.v1i0.18389.

\section{Publisher's Note}

Springer Nature remains neutral with regard to jurisdictional claims in published maps and institutional affiliations.

Ready to submit your research? Choose BMC and benefit from:

- fast, convenient online submission

- thorough peer review by experienced researchers in your field

- rapid publication on acceptance

- support for research data, including large and complex data types

- gold Open Access which fosters wider collaboration and increased citations

- maximum visibility for your research: over $100 \mathrm{M}$ website views per year

At BMC, research is always in progress.

Learn more biomedcentral.com/submissions 